\title{
O PLANEJAMENTO TERRITORIAL NO INSTITUTO GEOLÓGICO: REVISÃO E AVALIAÇÃO DA EXPERIÊNCIA
}

\author{
Antonio Gonçalves PIRES NETO \\ Sueli YOSHINAGA
}

\begin{abstract}
RESUMO
A metodologia utilizada pelo Instituto Geológico para planejamento e avaliação do uso da terra vem sendo desenvolvida com base em projetos multidisciplinares da área das Geociências, desde 1988. Estes estudos indicaram que as abordagens da Paisagem (Tipos de Terreno) e a Geológico-Geotécnica, desde que usadas de modo complementar e dentro dos objetivos e escalas para as quais foram desenvolvidas, propiciam ao técnico planejador uma visão holística e dinâmica dos componentes e atributos do meio físico. Dentro desta perspectiva e com base numa análise do geral para o particular, pode-se ter uma visão integrada dos processos internos e externos do meio físico e assim responder de modo mais eficiente às questões referentes ao uso e ocupação do solo.
\end{abstract}

\section{ABSTRACT}

The methodology utilized by the Instituto Geológico for planning and land evaluation was developed along multidisciplinary geoscientific projects since 1988. These studies indicate that the Landscape concept and geologic-geotechnical approaches, used as complementary tools in accordance to project aims and work scales, can be more efficient in answering questions concerning the anthropic use of land. Another important consideration on this type of approach is its capability of supporting an holistic and dynamic data base related to internal and external environmental processes, and to answer management and planning questions.

\section{INTRODUÇÃO}

Este trabalho apresenta uma análise das experiências de integração de dados do meio físico, obtidos nos projetos executados pelo IG, dentro do Programa "Cartas GeológicoGeotécnicas para o Planejamento Ambiental da Região de Sorocaba e Campinas", executados nos municípios de Sorocaba (IG, 1990), Itu (IG, 1991) e Campinas (IG, 1993).

Os projetos compreenderam a elaboração de estudos básicos de geologia e geomorfologia, e aplicadas: hidrogeologia, recursos minerais e geotecnia, e uma análise integrada destes componentes e atributos do meio físico, de modo a fornecer:

a) avaliação sobre as potencialidades e fragilidades do meio físico;

b) diagnóstico do comportamento do meio físico ante as ações antrópicas (atividades: urbana, industrial e rural);

c) subsídios ao planejamento do uso e ocupação, e d) recomendações para o manejo dos recursos naturais disponíveis.

\section{ESTUDOS REALIZADOS}

No decorrer da execução dos projetos, foram identificados alguns aspectos de relevante importância para a consolidação dos estudos geológicos voltados ao planejamento, destacando-se: a evolução do método de integração, o aprimoramento das equipes e a importância da questão sócio-econômica na área estudada, à medida em que elas auxiliam na definição de enfoque geral do projeto em conseqüência principalmente dos meios de maior e menor grau de urbanização da área.

Durante as várias experiências de integração dos dados geológicos, ocorreu uma maior ordenação dessas informações e maior clareza quanto ao método utilizado, denotando-se mudanças significativas no modo de análise e sistematização dos vários atributos do meio físico, bem como na apresentação dos dados 
obtidos e no tipo de subsídios oferecidos ao Planejamento Municipal.

Essa evolução foi propiciada principalmente pelas mudanças no tipo de parâmetro e no critério de definição das unidades de integração.

No município de Sorocaba (IG, 1990), para a integração dos dados do meio físico utilizouse o critério de Unidades Homogêneas, definidas principalmente com base no substrato rochoso, à exceção da Unidade IVB, diferenciada por sua declividade superior a $30 \%$.

Neste trabalho considerou-se como pressuposto que o substrato rochoso impõe regularidade geotécnica, hidrogeológica e de recursos naturais às unidades de integração. Deste modo, definiram-se seis Unidades Homogêneas, que estão caracterizadas na figura 1.

Em Itu, aprofunda-se o conceito de Unidade Homogênea, definindo-a como "área geograficamente delimitada com as mesmas potencialidades e fragilidades e, por conseguinte, apresenta respostas semelhantes a uma intervenção específica do homem" (IG, 1991). Neste estudo, as dez Unidades Homogêneas identificadas foram definidas com base no substrato rochoso e no relevo. Essas unidades foram apresentadas em mapa de escala 1:50.000 (Fig. 2) e caracterizadas em quadrosíntese.

No estudo de Campinas, a integração dos dados foi feita na forma de Tipos de Terrenos, que na abordagem utilizada constitui uma área diferenciada por meio de similaridade do arranjo espacial dos seus componentes e atributos, bem como pela recorrência de seus arranjos. Os terrenos foram definidos com base no relevo e caracterizados pelo substrato rochoso e pelo solo. A vulnerabilidade natural do aquíf́ero e os processos morfogenéticos superficiais predominantes foram também utilizados como elementos desta caracterização.

$\mathrm{Na}$ análise integrada foram ainda consideradas as áreas de maior produtividade similar de água subterrânea e as de maior potencial mineral (cerâmica vermelha, brita, pedra ornamental e talhe e/ou cantaria); as áreas de maior risco à erosão em sulcos, à formação de voçorocas e a enchentes; e as áreas de preservação regulamentadas.

Os terrenos assim caracterizados foram avaliados quanto à ocupação urbana, industrial e agrícola, sendo os problemas existentes e/ou esperados e as recomendações necessárias para sua mitigação apresentados na forma de Relatório de Integração. Os Tipos de Terreno, seus componentes e atributos foram apresentados em mapa na escala 1:50.000, que é mostrado esquematicamente na figura 3.

Esta mudança de critério deveu-se ao fato de o conceito de Unidade Homogênea, encontrado na literatura nacional e internacional, estar vinculado essencialmente à Geologia de Engenharia e à Cartografia Geotécnica, as quais desde os seus primórdios têm-se desenvolvido associadas à resolução dos problemas geológico-geotécnicos gerados pela implantação de obras de engenharia civil e pela urbanização desordenada do meio físico, caracterizando uma abordagem essencialmente voltada a estudos de detalhe e ao Planejamento Urbano, e que é pouco eficiente para estudos regionais e para o Planejamento Territorial.

Nos estudos do município de Campinas adotou-se o conceito de Tipos de Terreno, utilizado por PIRES NETO \& LEPSCH (1992) no município de Nova Friburgo, com o objetivo de ampliar a base de avaliação do meio físico, no sentido de um planejamento de caráter territorial e ambiental.

A opção por esta abordagem foi reforçada pelo fato de ela prever a elaboração de mapas morfopedológicos, de classificação da terra e de capacidade de uso (LEPSCH et al., 1983) para as atividades agropecuárias, que na maior parte dos estudos do meio físico, elaborados somente por profissionais de geologia, não se encontra realizada, o que em muito limita o Planejamento, a medida em que não avalia as potencialidades e fragilidades do meio físico frente a ocupações de agropecuária e silvicultura.

Quanto ao processo de integração dos dados, nos projetos Sorocaba e Itu predominou o uso do método paramétrico de classificação. Segundo MABBUTT (1968) este sistema é "baseado no estudo em separado e na classificação individual dos componentes do terreno, e cada classificação desenha um produto com o propósito específico obtido pela análise das rochas, do solo, do relevo, da hidrografia, dentro de uma visão sintética da realidade".

Nos estudos de Campinas houve uma adaptação do sistema paramétrico com a junção de critérios da Abordagem de Paisagem; este último, além de envolver o relevo, o solo, as rochas e a vegetação, classificou o terreno pelos padrões de suas paisagens, que são diferenciados com base na similaridade do arranjo espacial dos componentes da paisagem e 
pela recorrência destes arranjos (MABBUTT, 1968). Nesse processo o mapa final de integração foi elaborado pela superposição de dois mapas. Um apresentando as principais potencialidades e fragilidades do meio físico obtidas por intermédio do processo paramétrico, que fornece melhores informações sobre os atributos do meio físico; e outro que apresenta os terrenos, definidos pela análise da paisagem, que melhor permite a explicitação das inter-relações entre os componentes do meio físico.

\section{CONSIDERAÇÕES FINAIS}

A partir da avaliação das experiências do Instituto Geológico sobre os estudos integrados do meio físico para planejamento, constatou-se que a integração não se deve restringir apenas a fornecer uma síntese simplificada dos conhecimentos do meio físico para planejadores, mas sim proporcionar ao técnico uma visão integrada e dinâmica do espaço físico e conseqüentemente permitir respostas, de modo cada vez mais eficiente para a resolução dos problemas relacionados à ocupação racional do espaço geográfico.

Assim, constata-se que os estudos do meio físico voltados ao planejamento territorial devem adotar o seguinte procedimento:

- $1^{\text {a }}$ Etapa: Estudos Regionais (escalas $1: 100.000$ e $1: 250.000$ ), para definição das Unidades de Terreno, indicando suas potencialidades e fragilidades, bem como apontando diretrizes gerais de planejamento e a localização de áreas críticas;

- 2a Etapa: Estudos de Detalhe (escalas 1:25.000 ou maiores) para identificação de Unidades Homogêneas e avaliação de problemas de riscos e impactos ocasionados pelas diversas atividades antrópicas.

Deste modo, os estudos regionais devem apresentar uma visão integrada das interrelações similares das várias características do meio físico, em que o mapa-síntese tem por finalidade demonstrar estas relações e transmitir a visão integrada do espaço estudado.

Nesta perspectiva, os estudos de integração do meio físico voltados para o Planejamento Territorial e para a Análise Ambiental podem ser elaborados com base nos seguintes pressupostos:

1. O espaço analisado é o Terreno, que é uma área diferenciada pela similaridade do arranjo de seus componentes e atributos, bem como pela recorrência destes arranjos;

2. O Tipo de Terreno é definido: 1) por seus componentes - rochas (constituição), morfografia e morfometria (forma) e solos (cobertura detrítica); 2) por seus atributos - fragilidade e potencial natural (diante das diversas atividades antrópicas).

3. O Tipo de Terreno é delimitado com base no relevo, que é considerado como uma síntese histórica e dinâmica das interações que ocorrem entre o substrato rochoso, o clima e os movimentos tectônicos ao longo do tempo.

4. O Mapa de Terreno deverá ser obtido a partir da análise integrada de seus componentes dentro da abordagem de paisagem e pela avaliação de seus atributos executados pelo estudo da abordagem paramétrica.

Os estudos de detalhe a serem executados dentro de uma abordagem geotécnica, têm como objetivo apontar resoluções para a mitigação do problema já existente ou esperado, detectados na consecução dos estudos regionais, focalizando-se preferencialmente: a recuperação de áreas degradadas pela mineração; os problemas geológico-geotécnicos por tipo de ocupação; os processos erosivos em estágios avançados, e a contaminação de águas subterrâneas (poço-fossa, disposição de resíduos sólidos domésticos e industriais).

Dentro do procedimento adotado para a execução dos estudos de planejamento, é proposta ainda a elaboração de Manuais de Orientação sobre o manejo e a conservação do meio físico, visando à mitigação dos impactos.

Por fim, a adoção desses procedimentos procura dar aos estudos integrados do meio físico, com enfoque no Planejamento Territorial e Análise Ambiental, uma maior eficiência para: apontar diretrizes de manejo do meio físico e para implantação dos diversos modos de uso e ocupação do solo; indicar resoluções aos problemas de degradação já existentes; orientar o usuário destes estudos na adoção de uma atitude que leve em conta o uso racional do meio físico e o planejamento das atividades antrópicas, de modo a mitigar seus impactos. 


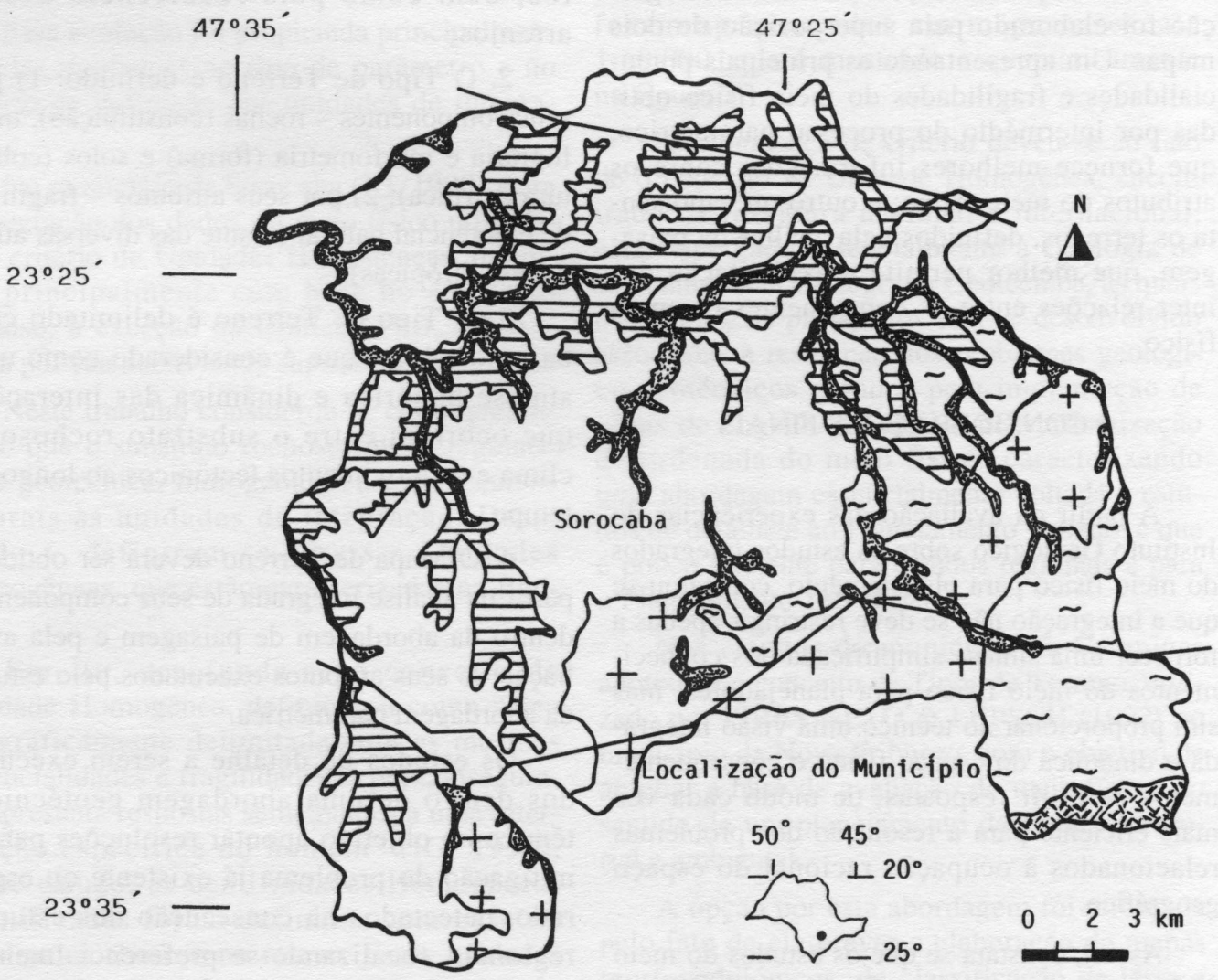

\section{LEGENDA}

\begin{tabular}{|c|c|c|c|}
\hline \multicolumn{2}{|c|}{$\begin{array}{c}\text { UNIDADES } \\
\text { HOMOGENEAS }\end{array}$} & \multirow{2}{*}{$\begin{array}{l}\text { SETORES DO RELEVO } \\
\text { PLANICIES ALUVIAIS } \\
(500-550 \mathrm{~m})\end{array}$} & CARACTERIZAÇAO GERAL \\
\hline I & $\because$ & & $\begin{array}{l}\text { Sedimentos inconsol idados impróprios para lotea- } \\
\text { mentos. Potencial mineral de areias e argilas. } \\
\text { Aquiferos com capacidade l imitada e vulnerávei. }\end{array}$ \\
\hline IIA & & \multirow{2}{*}{$\begin{array}{l}\text { COLINAS MEDIAS E } \\
\text { ESPIGOES APLAINADOS } \\
(600-650 \mathrm{~m})\end{array}$} & $\begin{array}{l}\text { Sedimentos predominantemente arenosos mais apta } \\
\text { a loteamentos. Aquifero com vazao moderada } \\
\text { vulnerabil idade pouco superior a IIB. }\end{array}$ \\
\hline IIB & & & $\begin{array}{l}\text { Sedimentos predominantemente argilosos. Fonte de de } \\
\text { argila para ceramica vermelha. Restriçoes a lo } \\
\text { teamentos. Aquifero com vazao pouco inferior a } \\
\text { IIA. }\end{array}$ \\
\hline III & & $\begin{array}{l}\text { MORROS E MORROTES } \\
\text { ALONGADOS } \\
(650-700 \mathrm{~m}) \\
\end{array}$ & $\begin{array}{l}\text { Metassedimentos heterogêneos e textura variada } \\
\text { apta a loteamentos com restriçoes. Aquifero com com } \\
\text { baixa a média potencialidade, descontinuo e con- } \\
\text { trole estrutural. }\end{array}$ \\
\hline IVA & & \multirow{2}{*}{$\begin{array}{l}\text { ESCARPAS ROCHOSAS } \\
(750-900 \mathrm{~m})\end{array}$} & $\begin{array}{l}\text { Maciço granítico. Declividades } 15 \text { a } 25 x \text {. Poten- } \\
\text { cial mineral: brita, saibro e areia. Aquifero } \\
\text { com comportamento similar a III. Restriçoes a } \\
\text { loteamentos. }\end{array}$ \\
\hline IVB & & & $\begin{array}{l}\text { Maciço granítico. Declividades superiores a } 30 x \\
\text { Impropria para loteamentos. Restricoes ao poten- } \\
\text { cial mineral. Aquifero com comportamento similar } \\
\text { a III. }\end{array}$ \\
\hline
\end{tabular}




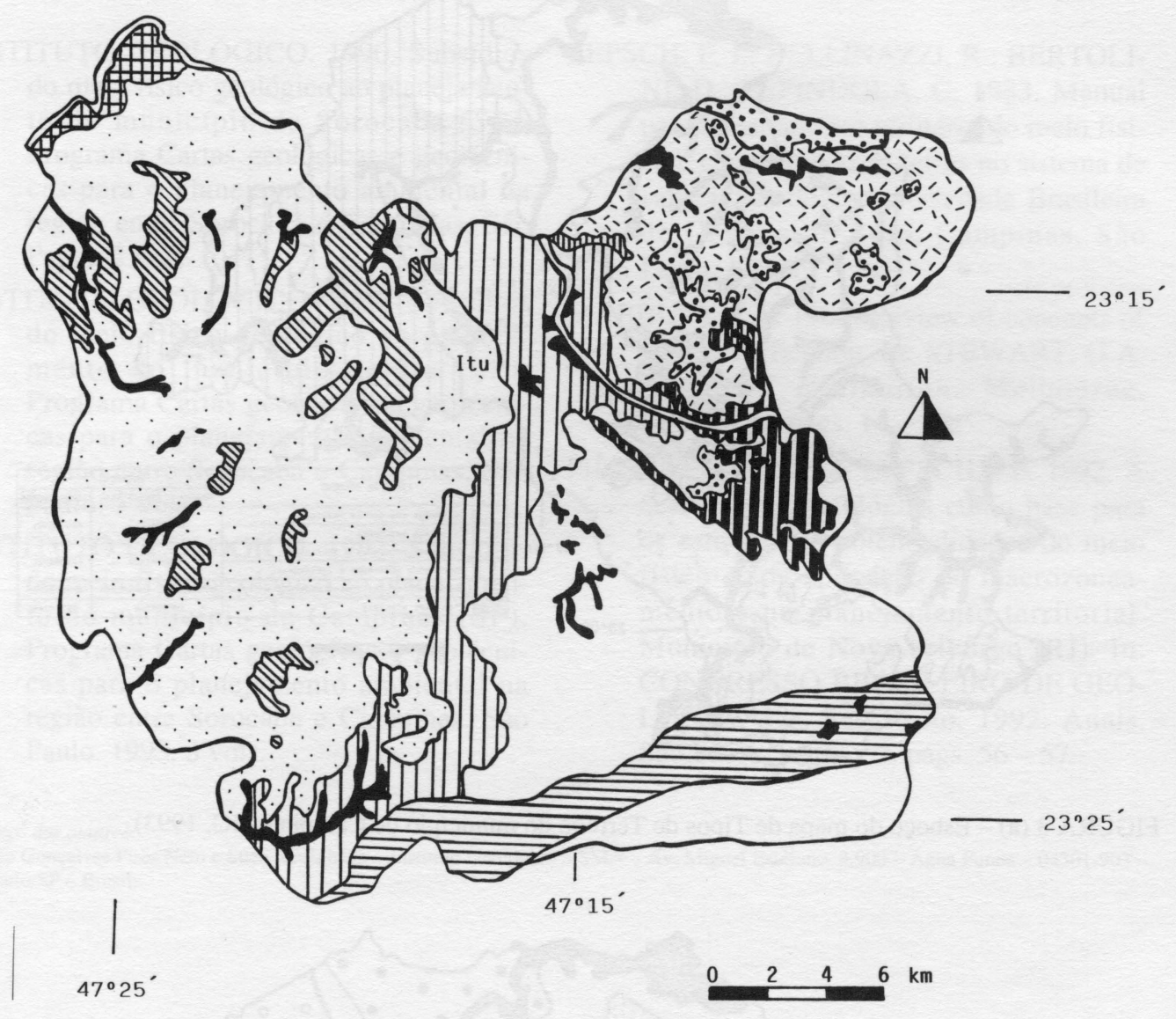

\begin{tabular}{|c|c|c|c|c|}
\hline \begin{tabular}{|l|} 
UNIDADES \\
HOOOGE - \\
NEAS
\end{tabular} & $\begin{array}{l}\text { TIPOS DE } \\
\text { RELEVO }\end{array}$ & UNIDADES GEOLOGICAS & RECURSOS MINERAIS & HIDROGEOLOGIA \\
\hline & $\begin{array}{l}\text { Sol inas de } \\
\text { Cimeire }\end{array}$ & \multirow[t]{4}{*}{$\begin{array}{l}\text { Macicos Graniticos } \\
\text { Itu eS Salto }\end{array}$} & & \multirow{6}{*}{$\begin{array}{c}\text { SISTEMA } \\
\text { AQUIFERO } \\
\text { CRISTALINO }\end{array}$} \\
\hline & $\begin{array}{l}\text { Morrotes } \\
\text { Oran iticos }\end{array}$ & & $\begin{array}{l}\text { Gran ito Ornamental } \\
\text { e Tailhe/Clantaria }\end{array}$ & \\
\hline & $\begin{array}{l}\text { Col inas } \\
\text { oraniticas }\end{array}$ & & $\begin{array}{l}\text { Mater ial de Emprés- } \\
\text { timo local izado }\end{array}$ & \\
\hline & $\begin{array}{l}\text { Relevos de } \\
\text { Transiçao }\end{array}$ & & Material de Empres- & \\
\hline & \begin{tabular}{|c|} 
Morrotes \\
Morrotess \\
Morrotes Gra-
\end{tabular} & $\begin{array}{l}\text { Maciçoo Granitico } \\
\text { Sorocaba }\end{array}$ & Granito Ornamental & \\
\hline & $\begin{array}{l}\text { Morrotes : } \\
\text { Morros Al Anga- } \\
\text { dos }\end{array}$ & $\begin{array}{l}\text { Metassed imentos } \\
\text { Grupo Sao Roque }\end{array}$ & $\underset{\text { Material de Empres- }}{\text { timo }}$ & \\
\hline & \multirow{3}{*}{ colinas } & $\begin{array}{l}\text { Argil itos: Lamitos: } \\
\text { Ritmitos: Subgrupo } \\
\text { Itarere }\end{array}$ & \multirow{2}{*}{$\begin{array}{l}\text { Argila para } \\
\text { Cerấmica Vermel ha }\end{array}$} & \multirow{2}{*}{$\begin{array}{r}\text { SISTEMA } \\
\text { AQUIFERO } \\
\text { TUBARAO }\end{array}$} \\
\hline & & $\begin{array}{l}\text { Aren itos Diversos } \\
\text { Subgrupo Itarare }\end{array}$ & & \\
\hline i & & $\begin{array}{l}\text { Complexo Itapira, } \\
\text { Grupo Sao Roque }\end{array}$ & definido acima & \multirow{3}{*}{$\begin{array}{l}\text { AQUIFERO } \\
\text { ALUVIONAR }\end{array}$} \\
\hline & $\begin{array}{l}\text { Terraco } \\
\text { Fluvial }\end{array}$ & $\begin{array}{l}\text { Areias com seixos } \\
\text { Terraços }\end{array}$ & Cascaltho & \\
\hline & $\begin{array}{l}\text { Planicie de } \\
\text { Inundasaoo }\end{array}$ & $\begin{array}{l}\text { Areias siltosas } \\
\text { Aluvioes }\end{array}$ & 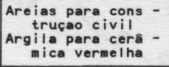 & \\
\hline
\end{tabular}




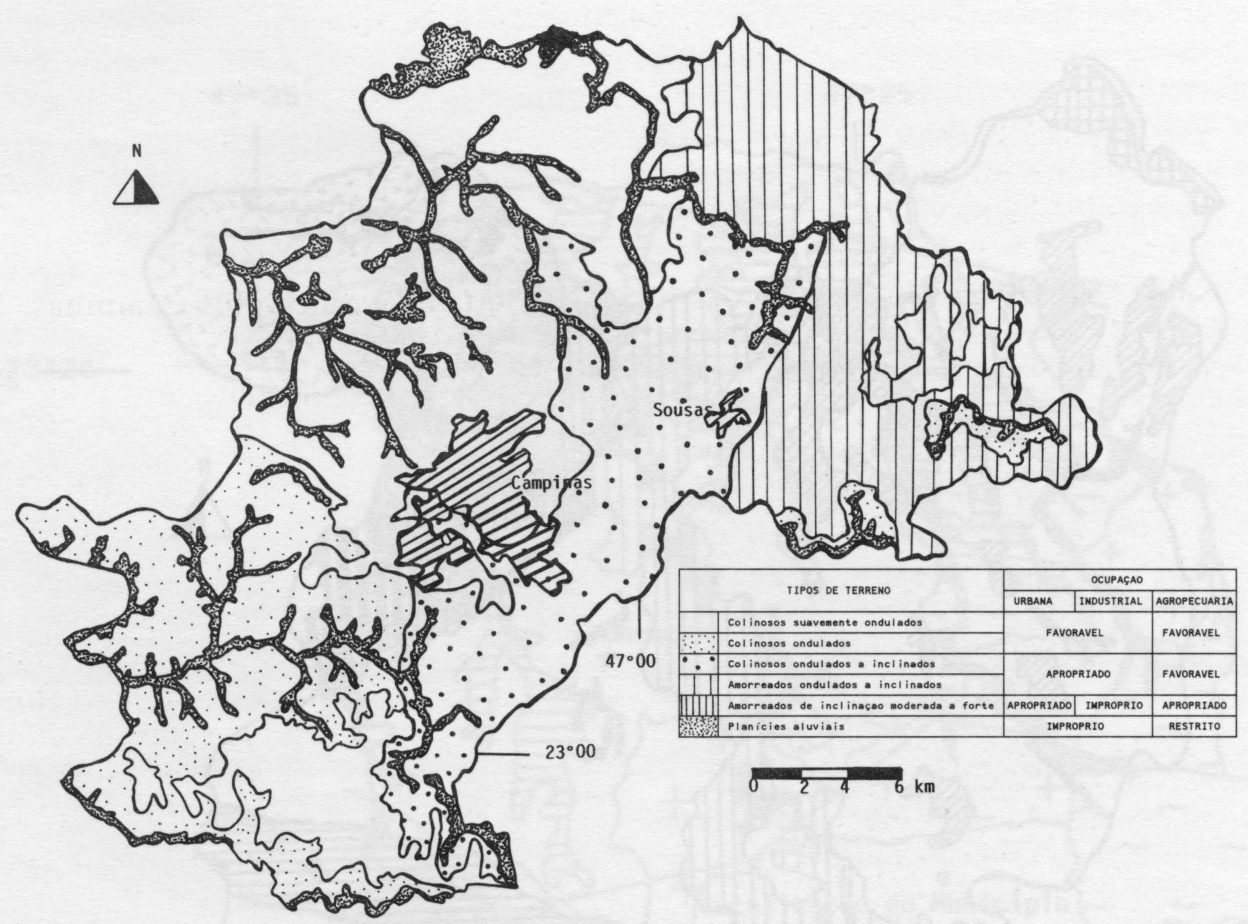

FIGURA 3 (a) - Esboço do mapa de Tipos de Terreno do município de Campinas (IG, 1993).

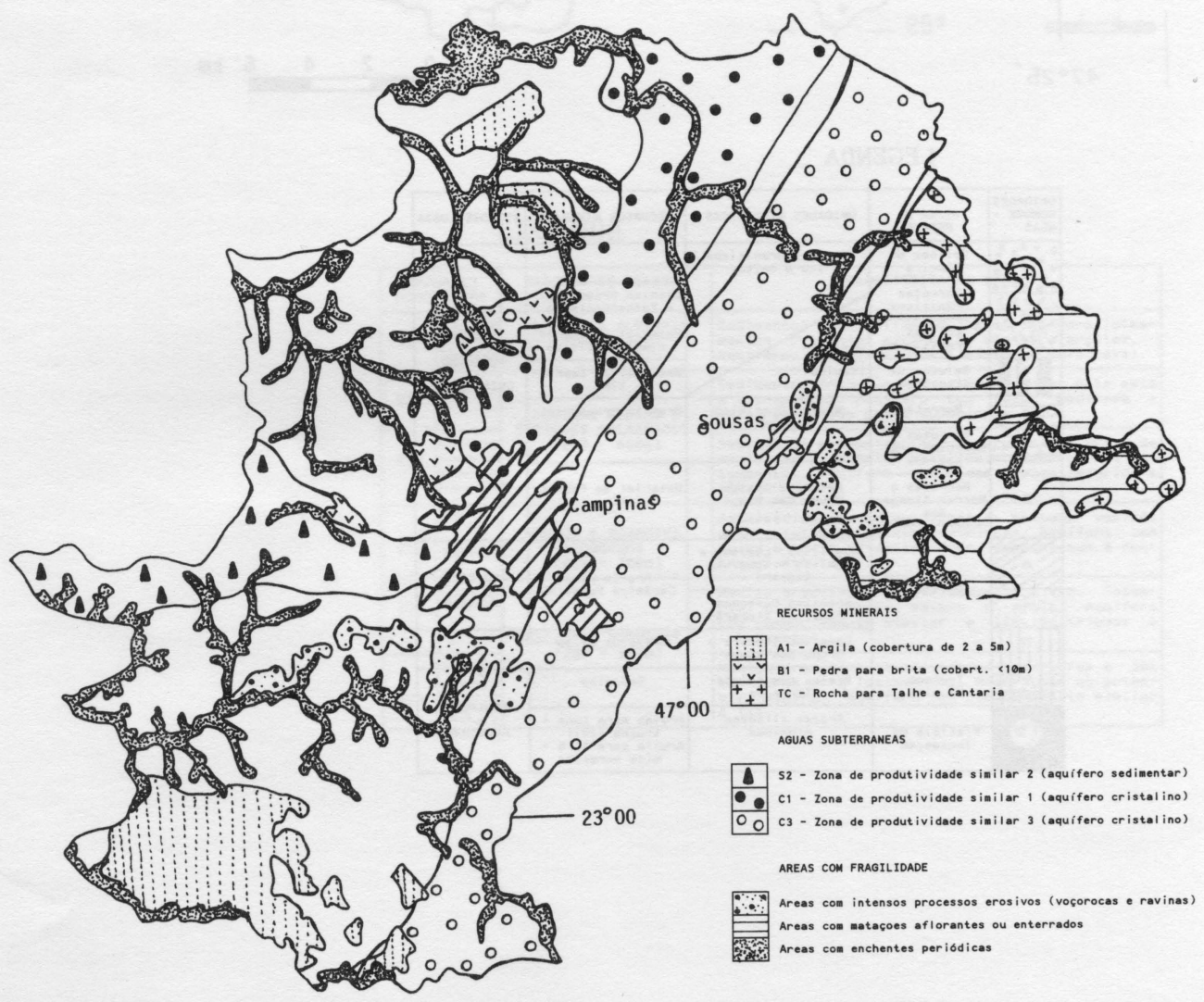

FIGURA 3 (b) - Esboço do Mapa de Tipos de Terreno do município de Campinas. Potencialidades e Fragilidades (IG, 1993). 


\section{REFERÊNCIAS BIBLIOGRÁFICAS}

INSTITUTO GEOLÓGICO. 1990. Subsídios do meio físico geológico ao planejamento do município de Sorocaba $(S P)$. Programa Cartas geológicas e geotécnicas para o planejamento ambiental na região entre Sorocaba e Campinas. São Paulo. 2 vols.

INSTITUTO GEOLÓGICO. 1991. Subsídios do meio físico geológico ao planejamento do município de Itu (SP). Programa Cartas geológicas e geotécnicas para o planejamento ambiental na região entre Sorocaba e Campinas. São Paulo. 3 vols.

INSTITUTO GEOLÓGICO. 1993. Subsídios do meio físico geológico ao planejamento do município de Campinas (SP). Programa Cartas geológicas e geotécnicas para o planejamento ambiental na região entre Sorocaba e Campinas. São Paulo. 1993. 3 vols.
LEPSCH, F. I.; BELLINAZZI, R.; BERTOLI-

NI, D.: ESPINDOLA, C. 1983. Manual para levantamento utilitário do meio físico e classificação de terras no sistema de capacidade de uso. Sociedade Brasileira de Ciência do Solo, Campinas, São Paulo, $176 \mathrm{p}$.

MABBUTT, J.A. 1968. Review of concepts of land classification. In: STEWART, G.A. ed. Land Evaluation. Melbourne, Macmillan. págs. $11-28$.

PIRES NETO, A.G. \& LEPSCH, I.F. 1992. A análise geomorfológica como base para os estudos das potencialidades do meio físico e sua aplicação no macrozoneamento e no planejamento territorial. Município de Nova Friburgo (RJ). In: CONGRESSO BRASILEIRO DE GEOLOGIA, 37ํㅗ São Paulo, 1992. Anais. São Paulo. SBG. v.2, págs. 56 - 57. 